\title{
Predictors of Early Readmission in Heart Failure Patients in an Inner-City Community Hospital
}

\author{
Fafa Xexemeku1 ${ }^{1}$ Arti Singh ${ }^{2}$, Yaw Amoateng Adjepong ${ }^{2}$, Stuart Zarich ${ }^{*}$ \\ ${ }^{1}$ Division of Cardiology, Department of Medicine, Bridgeport Hospital, Yale University, Bridgeport, USA \\ ${ }^{2}$ Department of Medicine, Bridgeport Hospital, Yale University, Bridgeport, USA \\ Email: "pszari@bpthosp.org
}

Received 2 July 2014; revised 3 August 2014; accepted 18 August 2014

Copyright (C) 2014 by authors and Scientific Research Publishing Inc.

This work is licensed under the Creative Commons Attribution International License (CC BY). http://creativecommons.org/licenses/by/4.0/

(c) (i) Open Access

\section{Abstract}

Heart failure (HF) is the most common hospital discharge diagnosis among the elderly. It accounts for nearly 1.4 million hospitalizations and $\$ 21$ billion in spending per year in the United States. Readmission rates remain high with estimates ranging from 15-day readmission rates of $13 \%, 30$ day readmission rates of $25 \%$, to 6-month readmission rates of $50 \%$. The Center for Medicare and Medicaid Services (CMS) has started penalizing hospitals with higher than expected readmission rates. Objective: To identify factors associated with increased 30-day readmission among heart failure patients in an inner-city community-based teaching hospital. Methods: A retrospective cohort study of patients with principal discharge diagnosis of acute Heart Failure between 2008 and 2010. Demographic, clinical characteristics, length of stay, discharge medications, disposition and all-cause 30-day readmission were abstracted from the hospital's administrative database and analyzed. Results: Almost 8 out of 10 patients were 65 years or older (mean age $75.4 \pm 14.3$ ) and $51 \%$ were female. The in-hospital mortality rate was $2.7 \%$ (95\% confidence interval [CI], $1.6 \%$ $4.3 \%$ ) with a median length of stay of 5.0 days (Interquartile range of $3-7$ ). The all-cause 30-day readmission rate was $17.7 \%$ (95\% CI $14.9 \%$ - 20.8\%). By univariate analysis, readmissions were predicted by black race, prior history of HF, length of stay of more than $\mathbf{7}$ days and discharge to extended care facility (ECF). By logistic regression analysis, black race (OR 2.4, 95\% CI 1.4 - 3.8), prior history of HF (OR 1.7, 95\% CI 1.5 - 2.6) and discharge to an ECF (OR 2.4, 95\% CI 1.5 - 3.7) were the independent predictors of 30-day readmission. HF accounted for $43.7 \%$ of the readmissions. Conclusion: Prior diagnosis of HF, black race, and discharge to an ECF were independent predictors of 30-day readmission in this cohort, and over half of the readmissions were for reasons other than HF.

\footnotetext{
"Corresponding author.
} 


\section{Keywords}

\section{Heart Failure, Readmissions, Predictors}

\section{Introduction}

The most common cause of both hospitalizations and readmissions in the medicare program is heart failure (HF) leading to nearly 1.4 million hospitalizations in 2007 alone [1] [2]. More than \$39 billion was spent on the care of patients with heart failure in 2010 in the United States with about \$21 billion spent on hospitalization [3].

Readmission rates after initial hospitalization for HF remain high. Patients experience an estimated 15-day readmission rate of $13 \%$, a 30 -day readmission rate of $25 \%$, and 6-month readmission rates of $50 \%$ [4] [5]. These readmissions have been estimated to cost the American public $>\$ 15$ billion per year [6]. Nearly $90 \%$ of the readmissions including those of HF are potentially preventable [1] [6].

Reducing readmissions has become a policy focus because it represents an opportunity to simultaneously improve quality and reduce costs. The National Quality Forum has endorsed hospital risk-standardized readmission rates (RSRRs) as performance measures, and the Centers for Medicare \& Medicaid Services publicly report these rates. The Patient Protection Affordable Care Act of 2010 has created new incentives to reduce readmissions using the publicly reported measures. From fiscal year 2013, the Centers for Medicare have started penalizing hospitals with higher than average HF readmissions rates. Hospitals with high readmission rates can lose up to $3 \%$ of their medicare reimbursement by 2015 [7].

Identification of high-risk patients prone to frequent readmissions is imperative to help clinicians focus their most resource-intensive disease management efforts on these patients. In addition, a better understanding of the major correlates of readmission could contribute to the development of more effective interventions. A number of predictors for HF have been identified, and research groups have proposed statistical models and risk scores to increase accuracy and precision to determine patient readmission risk after hospital discharge for HF [8]-[15]. Given the heterogeneous nature of the HF population, a "one-size fits-all" approach to risk stratification is not appropriate. Re-admission risks vary across population groups. This retrospective cohort study examines the predictors of heart failure readmission in an inner city hospital.

\section{Method}

This was a retrospective cohort study conducted in a 425-bed, inner-city, community-based, teaching hospital in the New England region of the United States. The catchment area of the hospital includes a large inner-city population with associated more affluent suburbs. The Institutional Review board (IRB) approved the study and waived requirement of informed consent from individual patients. All patients with a primary discharge diagnosis of heart failure between January 1, 2008 through December 31, 2010 were eligible for inclusion. Data were extracted from the administrative electronic database of the hospital using a uniform data abstract sheet. Abstracted records included demographic information (age, gender, race, ethnicity), payer status, admission and discharge diagnoses, co-morbid conditions, medications, major echocardiographic findings, length of stay, inhospital mortality and discharge disposition.

\section{Data Analysis}

For purposes of the study, subjects were categorized on the basis of race and ethnicity into White non-Hispanics (WHITES), Black non-Hispanics (Blacks), Hispanics, and all others. Patients' payer status was categorized as Medicare, Medicaid (including city welfare), Commercial Insurance, and self-Pay. Discharge disposition was classified as Home (with or without services), or Extended Care facility (including skilled nursing facility, long-term care, or rehabilitation facility) or Hospice care.

The primary outcome of interest was 30-day all cause re-admission. Secondary outcomes included CHF-specific 30-day re-admission, 7-day all cause re-admission, in-hospital mortality, and length of stay. For purposes of the study, the very first hospitalization for CHF within the study period was considered the index admission, and subsequent hospitalizations for the same patient were considered readmissions. 
The data were analyzed using Epiinfo. Non-parametric variables were compared using the Wilcoxon rank sum test. Differences between means were compared using the analysis of variance (ANOVA) or student t-test. Differences between proportions were compared using the chi-square test. 95\% confidence intervals were computed using exact binomials. A two-tailed p-value of $<0.05$ was considered statistically significant.

\section{Results}

A total of 712 patients, with mean age of $75.4+14.3$, were included in the study. The baseline characteristics of the patients are shown in Table 1 . About $78.9 \%$ were aged 65 years or older, $51 \%$ were women and the majority (70.7\%) was white. Significant co-morbid conditions included hypertension (80.4\%), chronic kidney disease stage 3 or worse (52.9\%), atrial fibrillation (43.1\%) and diabetes mellitus (45.3\%).

The median length of stay was 5 days and the overall in-hospital mortality rate was $2.7 \%$. Among the patients discharged from the hospital, the 30 -day all cause re-admission rate was $17.7 \%$ (95\% CI: $14.9 \%-20.8 \%)$. The major reasons for re-admission were CHF exacerbations (43.4\%), other cardiac conditions (11.5\%), infections

Table 1. Baseline characteristics of the patients.

\begin{tabular}{|c|c|}
\hline \multicolumn{2}{|c|}{ Overall ( $\mathrm{N}=712)$} \\
\hline Age, mean \pm SD & $75.4 \pm 14.3$ \\
\hline Age $\geq 65$ years & 547 (78.9\%) \\
\hline Male gender & 349 (49\%) \\
\hline \multicolumn{2}{|l|}{ Race } \\
\hline White & $502(70.7 \%)$ \\
\hline Black & $135(19.0 \%)$ \\
\hline Hispanic & $67(9.4 \%)$ \\
\hline Others & $9(0.9 \%)$ \\
\hline Body Mass Index median (IQR) & $28.2(24.3-34.9)$ \\
\hline \multicolumn{2}{|l|}{ Insurance } \\
\hline Medicare & $608(85.4 \%)$ \\
\hline Medicaid & 77 (10.8\%) \\
\hline Commercial & $22(3.1 \%)$ \\
\hline Self-pay & $5(0.7 \%)$ \\
\hline \multicolumn{2}{|l|}{ Discharge destination } \\
\hline Home & $486(70.4 \%)$ \\
\hline SNF & $192(27.8 \%)$ \\
\hline Hospice & $11(1.6 \%)$ \\
\hline Prior HF & $416(59.6 \%)$ \\
\hline Diabetes mellitus & $318(45.3 \%)$ \\
\hline Hypertension & $566(80.4 \%)$ \\
\hline Atrial fibrillation & $304(43.1 \%)$ \\
\hline Chronic obstructive pulmonary disease & $138(19.7 \%)$ \\
\hline Chronic kidney disease Stage III & $372(52.9 \%)$ \\
\hline Ejection fraction $\geq 50 \%$ & 294 (50.9\%) \\
\hline
\end{tabular}


(10.7\%), neurological conditions (7.4\%) and renal problems (6.6\%) as shown in Table 2.

From the univariate analyses, re-admitted patients were more likely to have pre-existing CHF at the time of their initial hospitalization, had prolonged initial hospital stay of at least 7 days, were Black or were discharged to an ECF as shown in Table 3.

Based on the multivariate logistic regression analyses, the major independent predictors of 30-day re-admission were discharge to an ECF (adjusted Odds ratio [OR] of 2.4, 95\% CI 1.54 - 3.73; p < 0.001), being Black (adjusted OR 2.4, 95\% CI 1.48 - 3.83; p = 0.001) and having prior CHF at the time of initial admission (adjusted OR 1.7, 95\% CI $1.50-2.58 ; \mathrm{p}=0.017$ ) as shown in Table 4.

\section{Discussion}

Readmission from heart failure has emerged as an important, potentially preventable, contributory cause of high hospital expenditure. Multiple factors, including female gender, low income status, single marital status, advanced age, co-morbid conditions (such as depression, coronary artery disease diabetes mellitus, atrial fibrillation, anemia, chronic kidney disease), worsening renal function, elevated cardiac troponin and increased length of initial hospitalization have been identified as potential predictors from previous studies [8] [13] [16]-[20].

In this retrospective cohort study, based on hospitalized patients in an inner city community-based teaching hospital, many of the prior identified predictors had no significant association with early heart failure re-admission rates. Three factors-prior heart failure diagnosis, discharge to extended care facility, and being of black race, emerged as the most important independent predictors for readmission in our population. The overall 30-day re-admission rate of $17.5 \%$ in our institution was lower than the national average and most (56.6\%) were for reasons other than worsening heart failure, similar to the findings of Muzzarelli et al. [16].

The association of black race and increased risk of re-admission in this cohort has been identified in some prior studies [8] [21]-[23]. This excess readmission rate was independent of insurance status or significant co-morbid conditions. It is likely that being black was a surrogate measure of other unmeasured factors such as low income and poor post-discharge follow-up, factors which have been associated with higher re-admission rates in other studies [22]. Prior heart failure found in our study as an independent predictor of early heart failure readmissions has been noted in some other studies [11] [24].

The higher readmission rates for patients discharged to SNF is not new [8] [25] though an earlier study suggested otherwise [21]. Patients discharged to ECF would tend to be older, sicker, less ambulatory, and more

\begin{tabular}{cc} 
Table 2. In-hospital and readmission outcomes. \\
\hline Length of stay (IQR) & 5 days (3 - 7) \\
In hospital mortality rate & $2.7 \%$ (95\% CI, 1.6\% - 4.3\%) \\
All-cause 30 day readmission rate & $17.7 \%$ (95\% CI, $14.9 \%-20.8 \%)$ \\
Reasons for Readmission & $43.4 \%$ \\
HF & $11.5 \%$ \\
Other cardiac diagnosis & $10.7 \%$ \\
Infections & $7.4 \%$ \\
Neurological & $6.6 \%$ \\
Renal & $6.6 \%$ \\
Pulmonary & $13.8 \%$ \\
Others & $14.4 \pm 9.2$ \\
Mean time to readmission \pm SD & \\
Days to readmission & $38(31.1 \%)$ \\
Within 7 days & $69(53.3 \%)$ \\
Within 14 days &
\end{tabular}


Table 3. Predictors of readmission: Univariate analysis.

\begin{tabular}{|c|c|c|c|}
\hline Characteristics & No Readmission (n[\%]) & Readmission (n[\%]) & p Value* \\
\hline \multicolumn{4}{|l|}{ Age } \\
\hline$<65$ Years & $117(80.1 \%)$ & 29 (19.9\%) & $\mathrm{p}=0.25$ \\
\hline 65 - 78 Years & $268(82.0 \%)$ & $59(18.0 \%)$ & $\mathrm{p}=0.27$ \\
\hline$>85$ Years & $183(84.3 \%)$ & $34(15.7 \%)$ & $\mathrm{p}=0.16$ \\
\hline Male Sex & $279(82.3 \%)$ & $60(17.7 \%)$ & $\mathrm{p}=0.5$ \\
\hline \multicolumn{4}{|l|}{ Race } \\
\hline Black & 99 (73.9) & $35(26.1)$ & $\mathrm{p}=0.003$ \\
\hline Non-Black & $469(84.4 \%)$ & $87(15.6 \%)$ & \\
\hline Body Mass Index $\geq 30$ & $206(80.2 \%)$ & $51(19.8 \%)$ & $\mathrm{p}=0.06$ \\
\hline Medicaid Insurance & $57(77.0 \%)$ & $17(23.0 \%)$ & $\mathrm{P}=0.1$ \\
\hline Non-Medicaid Insurance & $506(82.8 \%)$ & $105(17.2 \%)$ & \\
\hline Hypertension & 465 (93.0\%) & $93(7.0 \%)$ & $\mathrm{p}=0.43$ \\
\hline Diabetes Mellitus & $266(83.1 \%)$ & $52(16.9 \%)$ & $\mathrm{p}=0.29$ \\
\hline Atrial Fibrillation & $237(80.1 \%)$ & 59 (19.9\%) & $\mathrm{p}=0.09$ \\
\hline Chronic Obstructive Pulmonary Disease & $108(81.2 \%)$ & $25(18.8 \%)$ & $\mathrm{p}=0.35$ \\
\hline Obstructive Sleep Apnea & $60(80.0 \%)$ & $15(20.0 \%)$ & $p=0.29$ \\
\hline Prior HF & 317 (79.1\%) & $84(20.9 \%)$ & $\mathrm{p}=0.003$ \\
\hline Coronary Artery Disease & $287(82.0 \%)$ & $63(18.0 \%)$ & $\mathrm{p}=0.46$ \\
\hline Ejection Fraction $\geq 50 \%$ & $264(93 \%)$ & $20(7.0 \%)$ & $\mathrm{p}=0.13$ \\
\hline \multicolumn{4}{|l|}{ Estimated GFR } \\
\hline$<60$ & $294(82.3 \%)$ & $63(17.7 \%)$ & $\mathrm{p}=0.49$ \\
\hline$<30$ & 72 (79.1\%) & 19 (20.9\%) & $\mathrm{p}=0.19$ \\
\hline Albumin $<3 \mathrm{~g} / \mathrm{L}$ & $63(75.0 \%)$ & $21(25.0 \%)$ & $p=0.06$ \\
\hline Pneumonia & $109(82.6 \%)$ & $23(17.4 \%)$ & $p=0.42$ \\
\hline Pulmonary Edema on Chest x-Ray & 319 (89.9\%) & $64(10.1 \%)$ & $\mathrm{p}=0.2$ \\
\hline Acute Kidney Injury & $91(79.0 \%)$ & $23(21.0 \%)$ & $\mathrm{P}=0.16$ \\
\hline Length of Stay $>7$ Days & $113(75.8 \%)$ & $36(24.2 \%)$ & $\mathrm{p}=0.01$ \\
\hline Loop Diuretic & 395 (83.5\%) & $78(16.5 \%)$ & $\mathrm{p}=0.13$ \\
\hline Elevated Troponin & $66(76.6 \%)$ & $20(23.3 \%)$ & $\mathrm{p}=0.09$ \\
\hline Elevated ProBNP & $384(82.4 \%)$ & $82(17.6 \%)$ & $\mathrm{p}=0.17$ \\
\hline Discharge to Skilled Nursing Facility & $140(72.9 \%)$ & $52(27.1 \%)$ & $\mathrm{p}<0.001$ \\
\hline
\end{tabular}


Table 4. Predictors of readmission: Multivariate analysis.

\begin{tabular}{cccc}
\hline & Hazard Ratio & 95\% Confidence Interval & $\mathrm{p}$ Value \\
\hline Black Race & 2.4 & $1.48-3.83$ & $\mathrm{p}=0.001$ \\
Discharge to SNF & 2.4 & $1.54-3.73$ & $\mathrm{p}<0.001$ \\
LOS $>$ 7 days & 1.4 & $0.91-2.32$ & $\mathrm{p}=0.12$ \\
Prior History of HF & 1.7 & $1.50-2.58$ & $\mathrm{p}=0.017$ \\
\hline
\end{tabular}

likely to be depressed with their stay at the ECF compared to those discharged home. On one hand, ECF patients are more likely to adhere to their treatment regimens and are also more likely to be readily identified when they begin to decompensate as compared to those discharged home. However, these patients are frailer with multiple comorbidities and poorer performance status. Further studies would be needed to better understand this finding.

The study was limited by its retrospective nature, limitation to one institution, lack of exploration of the adequacy of post-discharge follow-up, and the limited information on psycho-social factors. Despite these limitations, the study has identified important predictive factors for 30-day re-admission that might provide initial basis for remedial action. Our study calls for the development of better networks to provide inner city black patients with better follow-up and education, as well as the need for hospitals to partner with ECFs to develop better strategies to manage the complex, elderly HF patient with multiple comorbidities. Once identified with HF, patients need consistent education and follow-up to enhance compliance and ensure they receive appropriate evidence based therapy to improve long term outcomes.

\section{References}

[1] Bueno, H., Ross, J.S., Wang, Y., Chen, J., Vidán, M.T., et al. (2010) Trends in Length of Stay and Short-Term Outcomes among Medicare Patients Hospitalized for Heart Failure, 1993-2006. JAMA, 21, 2141-2147. http://dx.doi.org/10.1001/jama.2010.748

[2] Rosamond, W., Flegal, K., Furie, K., Go, A., Greenlund, K., et al. (2008) Heart Disease and Stroke Statistics-2008 Update: A Report from the American Heart Association Statistics Committee and Stroke Statistics Subcommittee. Circulation, 4, e25-e146.

[3] Lloyd-Jones, D., Adams, R.J., Brown, T.M., Carnethon, M., Dai, S., et al. (2010) Heart Disease and Stroke Statistics-2010 Update: A Report from the American Heart Association. Circulation, 7, e46-e215.

[4] Keenan, P.S., Normand, S.L., Lin, Z., Drye, E.E., Bhat, K.R., et al. (2008) An Administrative Claims Measure Suitable for Profiling Hospital Performance on the Basis of 30-Day All Cause Readmission Rates among Patients with Heart Failure. Circulation: Cardiovascular Quality and Outcomes, 1, 29-37. http://dx.doi.org/10.1161/CIRCOUTCOMES.108.802686

[5] Jencks, S.F., Williams, M.V. and Coleman, E.A. (2009) Rehospitalizations among Patients in the Medicare Fee-forService Program. The New England Journal of Medicine, 360, 1418-1428. http://dx.doi.org/10.1056/NEJMsa0803563

[6] Hackbarth, G.M. and Reischauer, R.D. (2007) Medicare Payment Advisory Commission (MedCAP). Report to the Congress: Creating Greater Efficiency in Medicare. http://www.medpac.gov/documents/Jun07_EntireReport.pdf

[7] Bradley, E.H., Curry, L., Horwitz, L.I., Sipsma, H., Wang, Y., et al. (2013) Hospital Strategies Associated with 30-Day Readmission Rates for Patients with Heart Failure. Circulation: Cardiovascular Quality and Outcomes, 4, 444-450. http://dx.doi.org/10.1161/CIRCOUTCOMES.111.000101

[8] Silverstein, M.D., Qin, H., Mercer, S.Q., Fong, J. and Haydar, Z. (2008) Risk Factors for 30-Day Hospital Readmission in Patients $\geq 65$ Years of Age. Proceedings (Baylor University. Medical Center), 4, 363-372.

[9] Krumholz, H.M., Parent, E.M., Tu, N., Vaccarino, V., Wang, Y., et al. (1997) Readmission after Hospitalization for Congestive Heart Failure among Medicare Beneficiaries. Archives of Internal Medicine, 1, 99-104. http://dx.doi.org/10.1001/archinte.1997.00440220103013

[10] Ross, J.S., Chen, J., Lin, Z., Bueno, H., Curtis, J.P., et al. (2010) Recent National Trends in Readmission Rates after Heart Failure Hospitalization. Circulation: Heart Failure, 1, 97-103. http://dx.doi.org/10.1161/CIRCHEARTFAILURE.109.885210

[11] Krumholz, H.M., Chen, Y.T., Wang, Y., Vaccarino, V., Radford, M.J. and Horwitz, R.I. (2000) Predictors of Readmission among Elderly Survivors of Admission with Heart Failure. American Heart Journal, 139, 72-77. 
http://dx.doi.org/10.1016/S0002-8703(00)90311-9

[12] Philbin, E.F. and DiSalvo, T.G. (1999) Prediction of Hospital Readmission for Heart Failure: Development of a Simple Risk Score Based on Administrative Data. Rev Port Cardiol, 9, 855-856.

[13] Chin, M.H. and Goldman, L. (1997) Correlates of Early Hospital Readmission or Death in Patients with Congestive Heart Failure. American Journal of Cardiology, 79, 1640-1644. http://dx.doi.org/10.1016/S0002-9149(97)00214-2

[14] Felker, G.M., Leimberger, J.D., Califf, R.M., Cuffe, M.S., Massie, B.M., Adams Jr., K.F., Gheorghiade, M. and O’Connor, C.M. (2004) Risk Stratification after Hospitalization for Decompensated Heart Failure. Journal of Cardiac Failure, 10, 460-466. http://dx.doi.org/10.1016/j.cardfail.2004.02.011

[15] Yamokoski, L.M., Hasselblad, V., Moser, D.K., Binanay, C., Conway, G.A., Glotzer, J.M., Hartman, K.A., Stevenson, L.W. and Leier, C.V. (2007) Prediction of Rehospitalization and Death in Severe Heart Failure by Physicians and Nurses of the ESCAPE Trial. Journal of Cardiac Failure, 13, 8-13. http://dx.doi.org/10.1016/j.cardfail.2006.10.002

[16] Muzzarelli, S., Leibundgut, G., Maeder, M.T., Rickli, H., Handschin, R., Gutmann, M., et al. (2010) Predictors of Early Readmission or Death in Elderly Patients with Heart Failure. American Heart Journal, 160, 308-314. http://dx.doi.org/10.1016/j.ahj.2010.05.007

[17] Goldenberg, I., Moss, A.J., Hall, W.J., McNitt, S., Zareba, W., Andrews, M.L., Cannom, D.S. for the Multicenter Automatic Defibrillator Implantation Trial (MADIT) II Investigators (2006) Causes and Consequences of Heart Failure after Prophylactic Implantation of a Defibrillator in the Multicenter Automatic Defibrillator Implantation Trial II. Circulation, 113, 2810-2817. http://dx.doi.org/10.1161/CIRCULATIONAHA.105.577262

[18] Damman, K., Navis, G., Voors, A.A., Asselbergs, F.W., Smilde, T.D., Cleland, J.G.F., van Veldhuisen, D.J. and Hillege, H.L. (2007) Worsening Renal Function and Prognosis in Heart Failure: Systematic Review and Meta-Analysis. Journal of Cardiac Failure, 13, 599-608. http://dx.doi.org/10.1016/j.cardfail.2007.04.008

[19] Felker, G.M., Gattis, W.A., Leimberger, J.D., Adams, K.F., Cuffe, M.S., Gheorghiade, M. and O’Connor, C.M. (2003) Usefulness of Anemia as a Predictor of Death and Rehospitalization in Patients with Decompensated Heart Failure. American Journal of Cardiology, 92, 625-628. http://dx.doi.org/10.1016/S0002-9149(03)00740-9

[20] Manzano-Fernández, S., Boronat-Garcia, M., Albaladejo-Otón, M.D., Pastor, P., Garrido, I.P., Pastor-Pérez, F.J., Martínez-Hernández, P., Valdés, M. and Pascual-Figal, D.A. (2009) Complementary Prognostic Value of Cystatin C, N-Terminal Pro-B-Type Natriuretic Peptide and Cardiac Troponin T in Patients with Acute Heart Failure. American Journal of Cardiology, 103, 1753-1759. http://dx.doi.org/10.1016/j.amjcard.2009.02.029

[21] Alexander, M., Grumbach, K., Remy, L., Rowell, R. and Massie, B.M. (1999) Congestive Heart Failure Hospitalizations and Survival in California: Patterns According to Race/Ethnicity. American Heart Journal, 137, 919-927. http://dx.doi.org/10.1016/S0002-8703(99)70417-5

[22] Joynt, K.E., Orav, E.J. and Jha, A.K. (2011) Thirty-Day Readmission Rates for Medicare Beneficiaries by Race and Site of Care. JAMA, 305, 675-681. http://dx.doi.org/10.1001/jama.2011.123

[23] Philbin, E.F. and DiSalvo, T.G. (1999) Prediction of Hospital Readmission for Heart Failure: Development of a Simple Risk Score Based on Administrative Data. Journal of the American College of Cardiology, 33, 1560-1566. http://dx.doi.org/10.1016/S0735-1097(99)00059-5

[24] Vinson, J.M., Rich, M.W., Sperry, J.C., Shah, A.S. and McNamara, T. (1990) Early Readmission of Elderly Patients with Congestive Heart Failure. Journal of the American Geriatrics Society, 38, 1290-1295.

[25] Allen, L.A., Hernandez, A.F., Peterson, E.D., Curtis, L.H., Dai, D., Masoudi, F.A., Bhatt, D.L., Heidenreich, P.A. and Fonarow, G.C. (2011) Discharge to a Skilled Nursing Facility and Subsequent Clinical Outcomes among Older Patients Hospitalized for Heart Failure. Circulation: Heart Failure, 4, 293-300.

http://dx.doi.org/10.1161/CIRCHEARTFAILURE.110.959171 
Scientific Research Publishing (SCIRP) is one of the largest Open Access journal publishers. It is currently publishing more than 200 open access, online, peer-reviewed journals covering a wide range of academic disciplines. SCIRP serves the worldwide academic communities and contributes to the progress and application of science with its publication.

Other selected journals from SCIRP are listed as below. Submit your manuscript to us via either submit@scirp.org or Online Submission Portal.
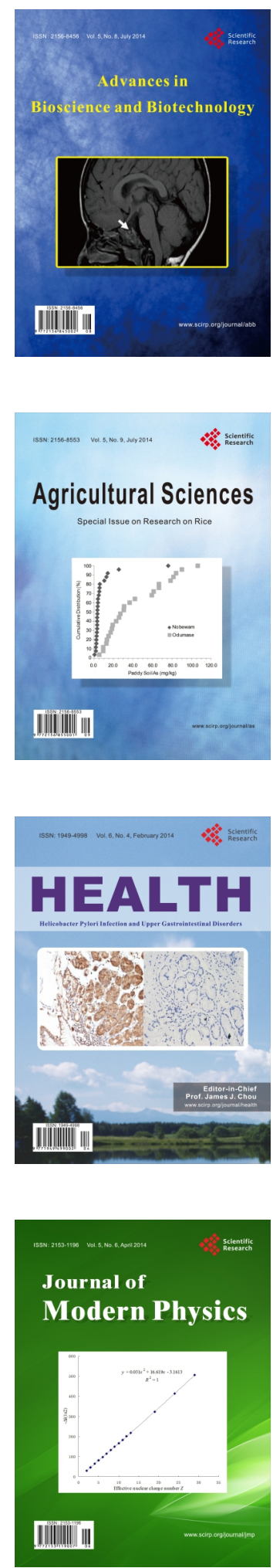
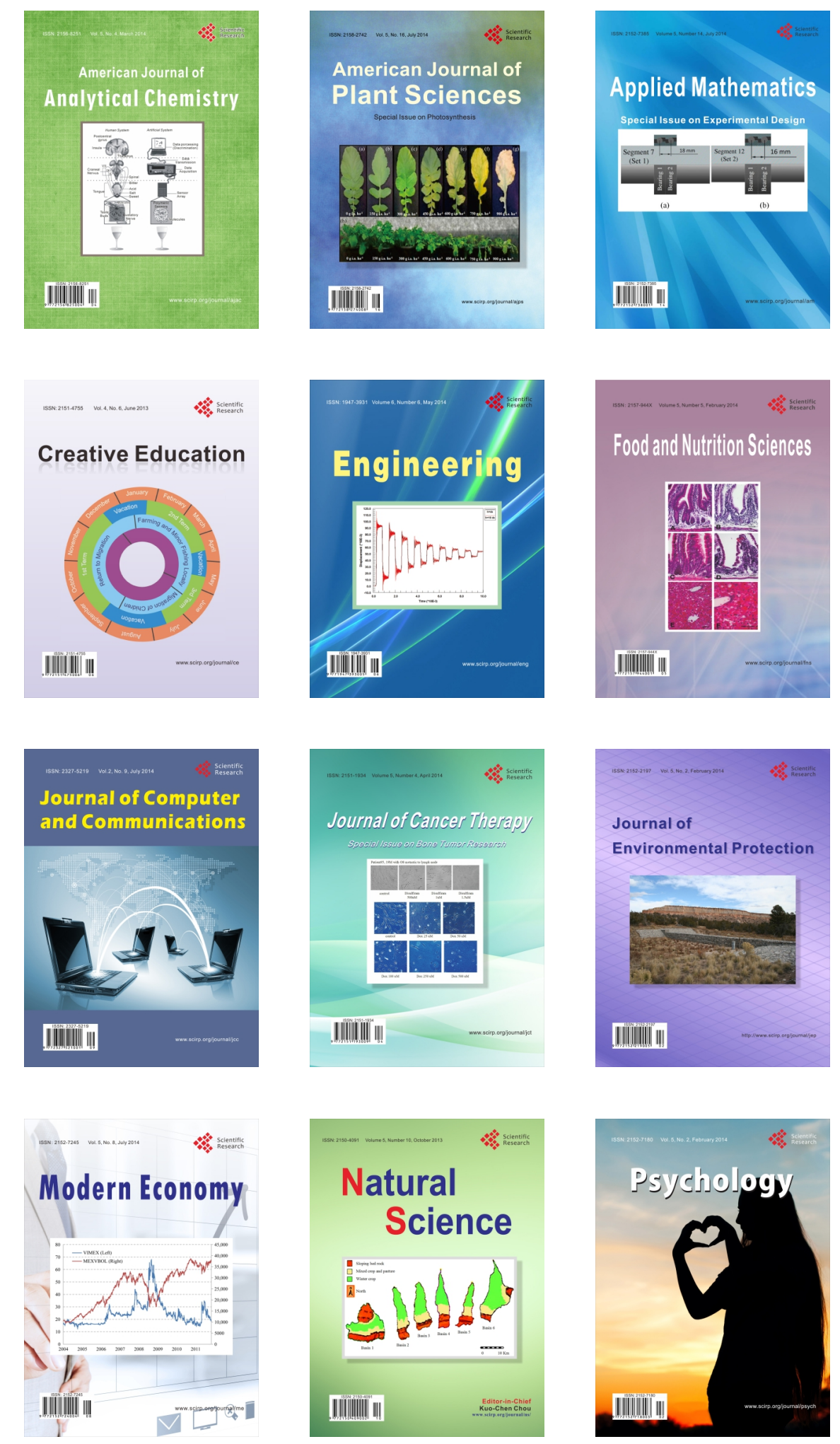